\title{
What does \#NYerORCoverChallenge mean for men in cardiothoracic surgery?
}

\author{
Susan C. Pitt, MD, MPHS
}

\footnotetext{
From the Division of Endocrine Surgery, Department of Surgery, University of Wisconsin School of Medicine and Public Health, Madison, Wis.

Disclosures: Author has nothing to disclose with regard to commercial support.

Received for publication June 28, 2017; accepted for publication June 30, 2017; available ahead of print Aug 3, 2017.

Address for reprints: Susan C. Pitt, MD, MPHS, Department of Surgery, University of Wisconsin, 600 Highland Ave, K4/738 CSC, Madison, WI 53792-7375 (E-mail: pitt@ surgery.wisc.edu; Twitter: @ susieQP8).

J Thorac Cardiovasc Surg 2017;154:1352-3

$0022-5223 / \$ 36.00$

Copyright (c) 2017 by The American Association for Thoracic Surgery

http://dx.doi.org/10.1016/j.jtcvs.2017.06.060
}

As surgeons, we all experienced tears of sadness and tears of joy. When I first saw Dr Nikki Stamp's \#NYerORCoverChallenge photo, I experienced both. The image evoked sadness with its profound symbolism: A female cardiothoracic $(\mathrm{CT})$ surgeon standing alone. I recognized her face through connections on social media and was excited because "the challenge" had reached Australia-it eventually spread to 6 of the 7 continents. Drs Antonoff and Stamp's article ${ }^{1}$ and the photos of thousands of other women surgeons embody many of the reasons why the \#NYerORCoverChallenge should be important for men in CT surgery.

The lone photos of Antonoff and Stamp vividly demonstrate the underrepresentation of women in CT surgery. ${ }^{2,3}$ Although a significant gap still exists in CT surgery and fields like orthopedics, urology, and neurosurgery, data show that the number of women in surgery are increasing. ${ }^{2,3}$ However, women surgeons, including those in CT, are drastically underrepresented on hospital boards, as deans, and department chairs; they are also disadvantaged when trying to obtain extramural funding or publish articles, even when controlling for the number of submissions. ${ }^{3-5}$

Antonoff and Stamp's article ${ }^{1}$ and The New Yorker challenge also exemplify the potential impact of social media on one's career and on all of medicine. I've never met Dr Stamp or Dr Tom Varghese, a thoracic surgeon at the University of Utah, but because of social media, I am well aware of their surgical practices, views on important issues, and academic activities. Future generations of CT surgeons are and will be very engaged in social media for learning, using podcasts and YouTube videos to supplement or even replace books. Social media can be used for teaching, networking, disseminating research findings or guidelines, and even educating and taking care of patients.

A third reason why Antonoff and Stamp article ${ }^{1}$ and the challenge should be important to all CT surgeons is that it demonstrates the power of social media. The

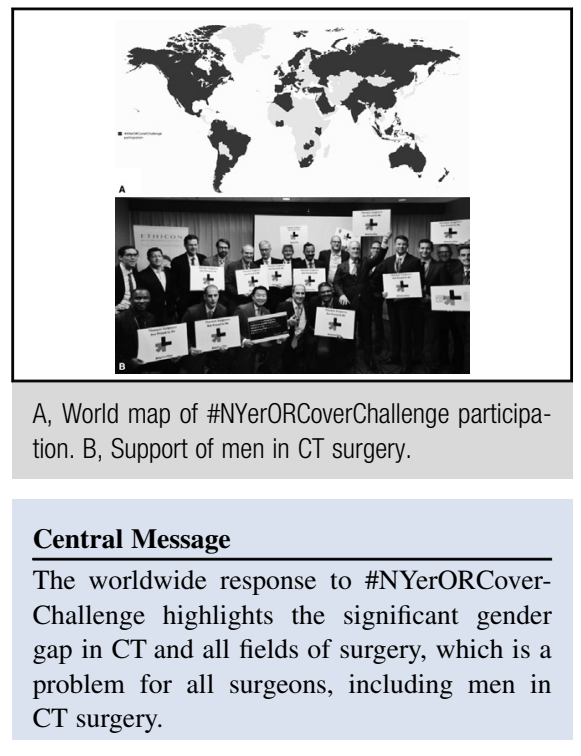

See Article page 1349 .

\#NYerORCoverChallenge reached women surgeons in at least 53 countries (Figure 1, A), including some where less than $1 \%$ of surgeons are female. Women from countries like Russia, Indonesia, Pakistan, Bosnia and Herzegovina, Ghana, Guatemala, and Uruguay participated. Female medical students from the likes of China and Venezuela joined in. People viewed a \#NYerORCoverChallenge tweet nearly 150 million times in the first month. As the authors note, this social media campaign is not the first nor will it be the last to impact our field.

In addition to drawing attention to inequities faced by female surgeons, the \#NYerORCoverChallenge also challenged male surgeons to help close the gender gap. The \#HeForSheChallenge was one response that encouraged male surgeons to post pictures holding up signs that say "\#HeForShe." These signs symbolize support for women surgeons and the pledge to ensure gender equity in the surgical workforce. At the recent 2017 Annual Meeting of The American Association for Thoracic Surgery meeting, male thoracic surgeons participated in this movement and began to advocate for their female colleagues (Figure 1, B). Together with Drs Antonoff and Stamp, I challenge you now to lead the way in making gender equity a reality in $\mathrm{CT}$ surgery. We are stronger together. 


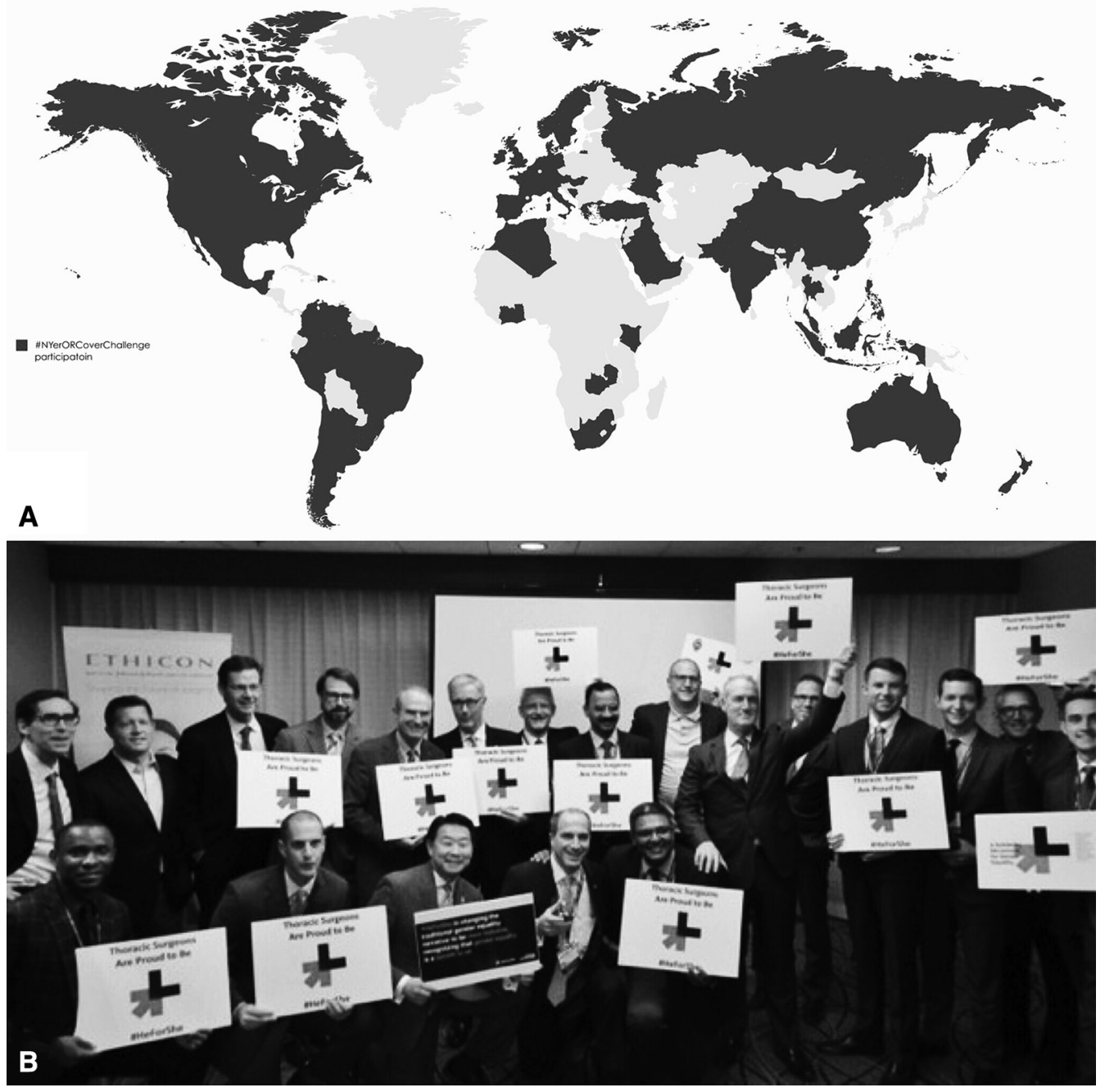

FIGURE 1. A, World map of \#NYerORCoverChallenge participation. B, Support of men in CT surgery.

\section{References}

1. Antonoff MB, Stamp N. The \#NYerORCoverChallenge: What it means for women in cardiothoracic surgery. J Thorac Cardiovasc Surg. 2017;154: 1349-51.

2. Rosati CM, Koniaris LG, Molena D, Blitzer D, Su KW, Tahboub M, et al. Characteristics of cardiothoracic surgeons practicing at the top-ranked US institutions. J Thorac Dis. 2016;8:3232-44.

3. Abelson JS, Chartrand G, Moo TA, Moore M, Yeo H. The climb to break the glass ceiling in surgery: trends in women progressing from medical school to surgical training and academic leadership from 1994 to 2015. Am J Surg. 2016;212:566-72

4. Mayer EN, Lenherr SM, Hanson HA, Jessop TC, Lowrance WT. gender differences in publication productivity among academic urologists in the United States. Urology. 2017:103:39-46.

5. Silver JK, Slocum CS, Bank AM, Bhatnagar S, Blauwet CA, Poorman JA, et al Where are the women? The underrepresentation of women physicians among recognition award recipients from medical specialty societies. PM R. June 9, 2017 [Epub ahead of print]. 